06.1

\title{
Получение гетерогенных наночастиц Al/BN в микроволновой плазме
}

\author{
(C) Ш. Корте ${ }^{1}$, М.К. Кутжанов ${ }^{1}$, А.М. Ковальский ${ }^{1}$, А.С. Конопацкий ${ }^{1}$, Д.Г. Квашнин ${ }^{1}$, Е.M. Приходько ${ }^{2}$, \\ П.Б. Сорокин ${ }^{1,3}$, Д.В. Штанский ${ }^{1}$, А.Т. Матвеев ${ }^{1, \uparrow}$ \\ ${ }^{1}$ Национальный исследовательский технологический университет „МИСиС“, Москва, Россия \\ ${ }^{2}$ Институт тепло- и массообмена им. А.В. Лыкова НАН Беларуси, Минск, Беларусь \\ ${ }^{3}$ Технологический институт сверхтвердых и новых углеродных материалов, Москва, Троицк, Россия \\ ฯ E-mail: matveev59@gmail.com
}

Поступило в Редакцию 13 декабря 2019г.

В окончательной редакции 26 февраля 2020 г.

Принято к публикации 27 февраля 2020 г.

Изучено взаимодействие смеси $\mathrm{Al}$ и нанопорошка $\mathrm{BN}$ с водородной СВЧ-плазмой. Методами рентгенофазового анализа, сканирующей и просвечивающей электронной микроскопии установлено образование нанокристаллов $\mathrm{AlN}$ и $\mathrm{AlB}_{2}$ в результате кратковременного $(\sim 30 \mathrm{~ms})$ взаимодействия пара $\mathrm{Al}$ с $h$-BN. Результаты исследований также указывают на образование гидрированного гексагонального нитрида бора $h$-BN-H. Проведен расчет критических сдвиговых напряжений для границ раздела $\mathrm{BN}$ с $\mathrm{Al}, \mathrm{AlB}_{2}$ и $\mathrm{AlN}$. Обсуждаются пути повышения прочности композиционных материалов на основе гексагонального нитрида бора и алюминия.

Ключевые слова: наночастицы, гетерогенные материалы, плазма, механические свойства.

DOI: 10.21883/PJTF.2020.10.49427.18154

Одним из подходов к созданию легких высокопрочных композиционных материалов (КМ) на основе алюминиевой матрицы является дисперсионное упрочнение наноструктурами нитрида бора (BN), обладающими уникальными характеристиками, такими как высокая химическая инертность, стойкость к высокотемпературному окислению и высокая механическая прочность на разрыв [1].

Необходимым условием высокой механической прочности КМ является равномерное распределение упрочняющей керамической нанофазы в металлической матрице, что может быть реализовано только в случае смачивания керамики расплавом металла. Было показано, что $\mathrm{Al}$ не смачивает поверхность BN вплоть до температуры 1373 K [2]. Это означает, что при введении нанопорошка $\mathrm{BN}$ в расплав $\mathrm{Al}$ он будет агломерировать в результате стремления системы снизить поверхностную энергию. В этом случае перспективным выглядит создание химически связанного слоя алюминия на поверхности наночастиц $\mathrm{BN}$, например, путем конденсации из пара, что изменит их поверхностную энергию.

В настоящей работе изучались гетерогенные частицы $\mathrm{Al} / \mathrm{BN}$, полученные методом испарения и конденсации пара $\mathrm{Al}$ при пропускании смеси порошков $\mathrm{Al}$ и $\mathrm{BN}$-наночастиц через водородную СВЧ-плазму.

Для синтеза гетерочастиц использовались нанопорошки $\mathrm{BN}$ (ОOО „Плазмотерм ${ }^{6}$, Россия) со средним размером частиц 20-80 nm и Al-пудра (ПАП-2, ГОСТ 5494-95). Однородная смесь исходных порошков с содержанием BN 25 wt.\% готовилась на трехосевом смесителе „ТУРБУЛА“ С 2.0. Для генерации СВЧ-плазмы использовался магнетрон мощностью $2 \mathrm{~kW}$ с частотой излучения $2.45 \mathrm{GHz}$. Водород производился генератором ГВЧ-25Д. Реактор изготовлен из кварцевой трубы с внутренним диаметром $25 \mathrm{~mm}$; охлаждение воздуш- ное. Давление водорода в реакторе поддерживалось на уровне $1 \cdot 10^{4} \mathrm{~Pa}$ при потоке $300 \mathrm{ml} / \mathrm{min}$. Расчетное время пребывания порошка в высокотемпературной зоне в интервале $1000-4000 \mathrm{~K}$ составляло примерно $30 \mathrm{~ms}$. Рентгенофазовый анализ проводился на аппарате „Дифрэй 401“ с использованием $\mathrm{Cr} K_{\alpha}$-излучения. Микроструктура гетерогенных частиц изучалась при помощи просвечивающего электронного микроскопа (ПЭМ) JEM-2100. Межплоскостные расстояния определялись методом быстрого фурье-преобразования. Теоретические расчеты проводились с помощью программного пакета VASP [3], основанного на теории функционала электронной плотности, с использованием базиса присоединенных плоских волн.

Было изучено влияние типа СВЧ-плазмы на процесс формирования гетерогенных наночастиц $\mathrm{Al} / \mathrm{BN}$. При использовании аргона в качестве плазмообразующего газа наблюдалось плавление частиц алюминия, что связано с низкой энергоемкостью аргоновой плазмы и недостаточной эффективностью процесса нагрева частиц порошка Al. В водородной плазме преимущественно происходило испарение частиц алюминия. Было изучено влияние давления водорода на стабильность плазмы и процесс испарения частиц Al. При давлении водорода в реакторе ниже $0.5 \cdot 10^{4} \mathrm{~Pa}$ испарение алюминия было недостаточно эффективным и количество оплавленных частиц Al существенно увеличивалось. При давлении водорода $2 \cdot 10^{4} \mathrm{~Pa}$ и выше плазма становилась неоднородной, что приводило к неравномерной обработке порошка. Оптимальным с точки зрения стабильности плазмы и эффективности испарения частиц Al было давление $1 \cdot 10^{4} \mathrm{~Pa}$.

Рентгенограмма образца после плазменной обработки представлена на рис. 1. Образец содержит две основные 
фазы: Al и сильнодефектный BN, у которого межплоскостное расстояние вдоль оси $c$ примерно составляет $0.35 \mathrm{~nm}$. Средний размер частиц $\mathrm{BN}$, определенный по методу Шеррера, составляет порядка $5 \mathrm{~nm}$, что подтверждается данными ПЭМ, приведенными далее.

Структурные исследования методом ПЭМ высокого разрешения выявили два характерных типа гетероструктур Al/BN. На рис. 2 показана относительно крупная частица алюминия (несколько десятков нанометров), на поверхности которой лежит наночастица $\mathrm{BN}$, состоящая из сильно искривленных атомных плоскостей, что характерно для турбостратной структуры (смесь гексагонального и ромбоэдрического ВN). Межплоскостное расстояние в наиболее упорядоченной области частицы $\mathrm{BN}$ составляет $0.375 \mathrm{~nm}$, что на $12 \%$ больше периода решетки $c$ кристаллического BN. Вблизи наночастицы BN расстояние между плоскостями $\mathrm{Al}_{(111)}$ увеличивается и составляет $0.237-0.241 \mathrm{~nm}$, что близко к расстоянию между плоскостями (101) гексагональной фазы AlN (ICDD 89-3446).

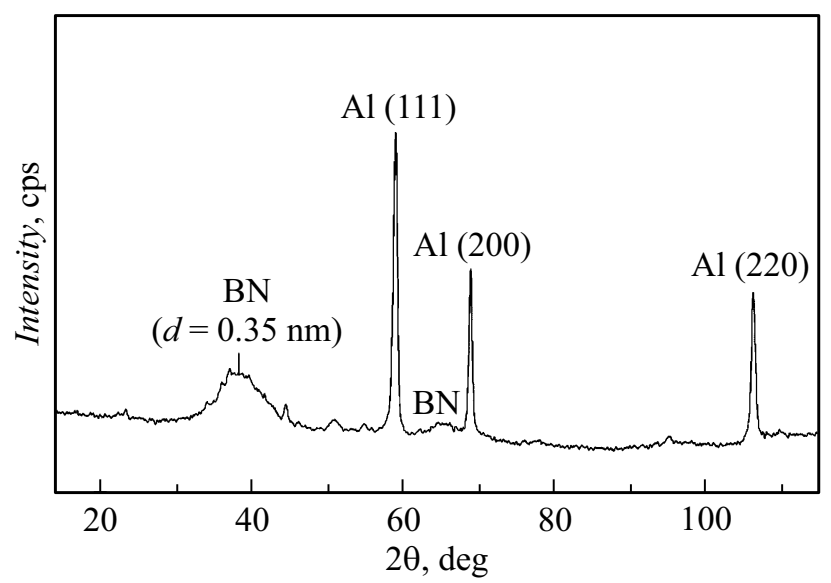

Рис. 1. Рентгенограмма смеси $\mathrm{Al} / \mathrm{BN}$ после обработки в водородной СВЧ-плазме.

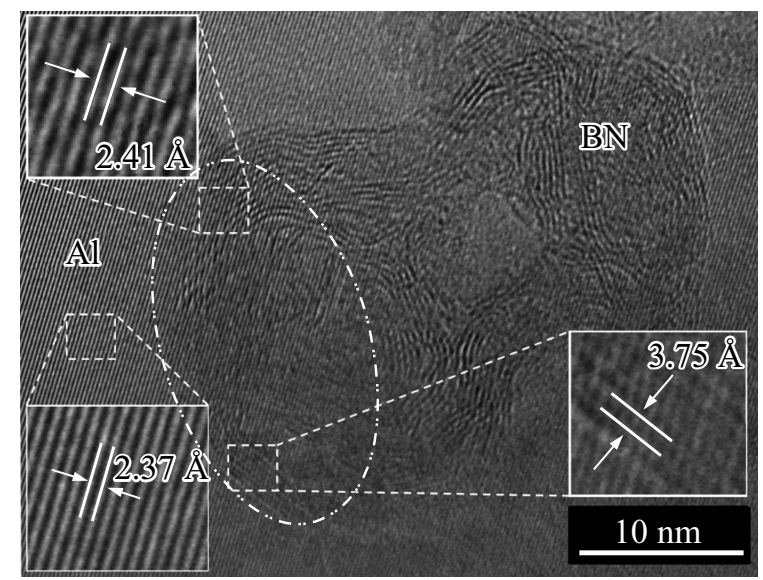

Рис. 2. Типичное ПЭМ-изображение высокого разрешения гетерочастицы Al/BN.

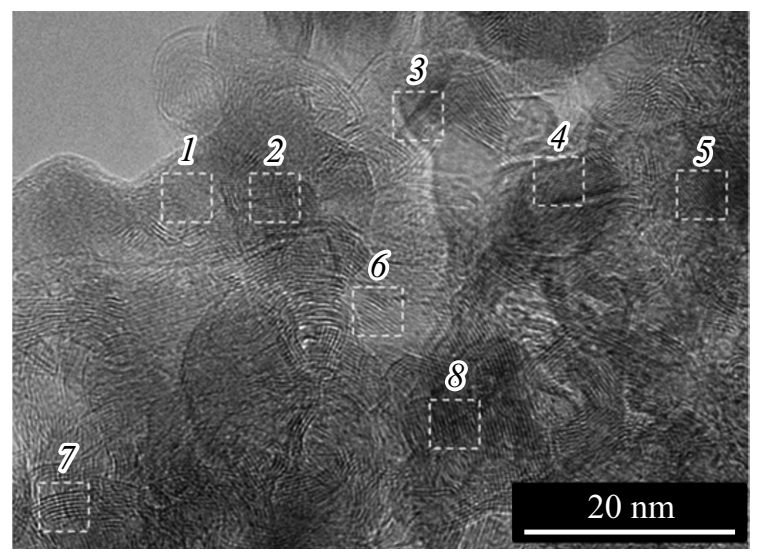

Рис. 3. ПЭМ-изображение высокого разрешения гетерочастицы $\mathrm{Al} / \mathrm{BN}$. Межплоскостные расстояния для отмеченных наночастиц приведены в табл. 1.

Таблица 1. Межплоскостные расстояния $d$ (nm) для наночастиц $1-8$, обозначенных на рис. 3

\begin{tabular}{c|c|c|c|c|c|c|c}
\hline 1 & 2 & 3 & 4 & 5 & 6 & 7 & 8 \\
\hline 0.290 & 0.280 & 0.262 & 0.263 & 0.245 & 0.341 & 0.345 & 0.36
\end{tabular}

Таблица 2. Рассчитанная величина критического сдвигового напряжения (GPa) для рассмотренных КМ на основе $h$-BN и $\mathrm{Al}, \mathrm{AlN}, \mathrm{AlB}_{2}$ с учетом атомов, находящихся на поверхности $h$-BN

\begin{tabular}{c|c|c}
\hline Граница раздела КМ & В-терминирование & N-терминирование \\
\hline $\mathrm{Al} / \mathrm{BN}$ & 0.44 & 0.56 \\
$\mathrm{AlN} / \mathrm{BN}$ & 1.05 & 0.78 \\
$\mathrm{AlB}_{2} / \mathrm{BN}$ & 11.6 & 9.7
\end{tabular}

ПЭМ-изображение высокого разрешения другого характерного участка образца представлено на рис. 3. Наблюдается образование гетерогенной смеси с размером отдельных структурных элементов менее $10 \mathrm{~nm}$. Межплоскостные расстояния, определенные в различных участках образца, приведены в табл. 1. Межплоскостное расстояние $0.245 \mathrm{~nm}$ может соответствовать плоскостям $\mathrm{AlN}_{(002)}$. Расстояние между атомными плоскостями, равное $0.262-0.263 \mathrm{~nm}$, хорошо согласуется с межплоскостным расстоянием для плоскости (100) фазы $\mathrm{AlB}_{2}$ (карта ICDD 65-3381). Ранее было показано, что фазы AIN и $\mathrm{AlB}_{2}$ образуются в процессе искрового плазменного спекания $\mathrm{Al}$ и $\mathrm{BN}$ [4]. Межплоскостные расстояния 0.28-0.29 nm не совпадают с межплоскостными расстояниями в фазах $\mathrm{Al}, \mathrm{AlN}, \mathrm{AlB}_{2}$ и $\mathrm{BN}$. Межплоскостные расстояния 0.341 и $0.345 \mathrm{~nm}$ близки к периодам гексагонального и ромбоэдрического ВN, для которых они составляют 0.33 и $0.34 \mathrm{~nm}$ соответственно (карты ICDD 85-1068 и 45-1171). Однако межплоскостное расстоя- 
ние $0.36 \mathrm{~nm}$ на 6-7\% превышает эти межплоскостные расстояния. Это можно объяснить тем, что данные наночастицы являются гидрированной формой слоистого нитрида бора $\mathrm{BN}-\mathrm{H}$ по аналогии с гидрированной формой углеродных нанотрубок [5] или гидрографитом [6]. Гидрирование $\mathrm{BN}$ в водородной плазме может приводить к увеличению межплоскостного расстояния вдоль оси $c$ в результате $s p^{3}$-гибридизации атомов В и $\mathrm{N}$ [7]. По-видимому, это является первым экспериментальным свидетельством возможности образования гидрированного $h$-BN. Следует отметить, что $\mathrm{BN}-\mathrm{H}$ представляет большой научный и практический интерес, поскольку теоретические расчеты предсказывают у него необычные свойства, такие как ферромагнетизм [7].

Таким образом, детальный ПЭМ-анализ высокого разрешения образцов после плазменной обработки показал, что их состав можно интерпретировать как смесь $\mathrm{Al}$ и наночастиц $\mathrm{AlN}, \mathrm{AlB}_{2}, h$-BN и $\mathrm{BN}-\mathrm{H}$. Нанокристаллиты $\mathrm{AlN}$ и $\mathrm{AlB}_{2}$ образовались при взаимодействии пара $\mathrm{Al}$ с наночастицами $\mathrm{BN}$, о чем свидетельствует отсутствие свободного алюминия в этих участках образца. Время такого взаимодействия составляет примерно $30 \mathrm{~ms}$, в течение этого времени материал находился в области высокой температуры.

Дополнительно был проведен расчет критического сдвигового напряжения для границ раздела $\mathrm{BN}$ и $\mathrm{Al}, \mathrm{AlN}$ и $\mathrm{AlB}_{2}$ в зависимости от типа атомов, находящихся на поверхности $h$-BN (табл. 2). Расчеты показывают, что границы раздела $\mathrm{AlB}_{2} / h-\mathrm{BN}$ и $\mathrm{AlN} / h-\mathrm{BN}$ имеют большее значение критического сдвигового напряжения, чем $\mathrm{Al} / h$-BN. Соответственно наивысшая прочность КМ на основе $\mathrm{Al}$ и $\mathrm{BN}$ может быть достигнута, если на границе раздела $\mathrm{Al} / \mathrm{BN}$ формируются фазы $\mathrm{AlN}$ или $\mathrm{AlB}_{2}$. Для образования тонких слоев этих фаз на поверхности наночастиц BN необходимо уменьшить концентрацию пара Al. Метод конденсации пара $\mathrm{Al}$ является перспективным для получения КM Al/BN.

\section{Финансирование работы}

Работа выполнена при финансовой поддержке Министерства образования и науки РФ (задание № 11.937.2017.ПЧ) в части определения механических свойств $\mathrm{Al} / \mathrm{BN}$ и Российского фонда фундаментальных исследований (договор № 18-58-00019/19) в части получения гетерогенных наночастиц в водородной СВЧ-плазме. Ш. Корте благодарит Министерство образования и науки РФ (программа повышения конкурентоспособности НИТУ „МИСиС“, грант № К2А-2018-037).

\section{Конфликт интересов}

Авторы заявляют, что у них нет конфликта интересов.

\section{Список литературы}

[1] Shtansky D.V., Firestein K.L., Golberg D.V. // Nanoscale. 2018. V. 10. P. 17477-17493. DOI: $10.1039 / \mathrm{c} 8 \mathrm{nr} 05027 \mathrm{a}$
[2] Fujii H., Nakae H., Okada K. // Acta Met. Mater. 1993. V. 41. P. 2963-2971. DOI: 10.1016/0956-7151(93)90111-5

[3] Gao F., He J., Wu E., Liu S., Yu D., Li D., Zhang S., Tian Y. // Phys. Rev. Lett. 2003. V. 91. P. 015502-015506. DOI: 10.1103/PhysRevLett.91.015502

[4] Firestein K.L., Corthay S., Steinman A.E., Matveev A.T., Kovalskii A.M., Sukhorukova I.V., Golberg D., Shtansky D.V. // Mater. Sci. Eng. A. 2017. V. 681. P. 1-9. DOI: $10.1016 /$ j.msea.2016.11.011

[5] Pekker S., Salvetat J.-P., Jakab E., Bonard J.-M., Forró L. // J. Phys. Chem. B. 2001. V. 105. P. 7938-7943. DOI: $10.1021 / \mathrm{jp} 010642 \mathrm{o}$

[6] Antonov V.E., Bashkin I.O., Bazhenov A.V., Bulychev B.M., Fedotov V.K., Fursova T.N., Kolesnikov A.I., Kulakov V.I., Lukashev R.V., Matveev D.V., Sakharov M.K., Shulga Y.M. // Carbon. 2016. V. 100. P. 465-473. DOI: 10.1016/j.carbon.2015.12.051

[7] Tang S., Cao Z. // Chem. Phys. Lett. 2010. V. 488. P. 67-72. DOI: $10.1016 /$ j.cplett.2010.01.073 